\title{
Neurosurgery restores late GH rise after glucose-induced suppression in cured acromegalics
}

\author{
R Attanasio, G Oppizzi, S Lodrini ${ }^{1}$, D Dallabonzana, M Barausse, P Orlandi, N DaRe ${ }^{2}$ and R Cozzi \\ Department of Endocrinology and ${ }^{2}$ Biochemistry, Niguarda Hospital, Milan, Italy and ${ }^{1}$ Department of Neurosurgery, C Besta Institute, Milan, Italy \\ (Correspondence should be addressed to R Cozzi, Division of Endocrinology, Ospedale Niguarda, Piazza Ospedale Maggiore 3, I-20162 Milano, Italy)
}

\begin{abstract}
Objective and design: A decrease of GH levels below $2 \mu \mathrm{g} / \mathrm{l}$ after an oral glucose tolerance test (OGTT) is still currently accepted as the gold standard for assessing cure in surgically treated acromegaly. Whether glucose-induced suppression of $\mathrm{GH}$ is accompanied by a restoration of normal $\mathrm{GH}$ late rebound has not yet been evaluated in this disease. In order to assess the restoration of normal GH regulation after removal of a pituitary adenoma, we have evaluated GH changes after an OGTT in a series of selected acromegalic patients (transsphenoidal surgery and lack of pituitary failure).

Methods: Twenty-nine patients (13 male, 16 female, age range 27-70 years) entered the study. Their neuroradiological imaging before neurosurgery showed microadenoma in 7 , intrasellar macroadenoma in 8 and macroadenoma with extrasellar extension in 14. Plasma GH levels were assayed up to $300 \mathrm{~min}$ after glucose administration $(75 \mathrm{~g}$ p.o.) and IGF-I on basal samples.

Results: Basal GH levels were below $5 \mu \mathrm{g} / \mathrm{l}$ in 20 patients and below $2 \mu \mathrm{g} / \mathrm{l}$ in 5 of these. Normal ageadjusted IGF-I levels were observed in 12 patients. GH values were suppressed below $2 \mu \mathrm{g} / \mathrm{l}$ during an OGTT in 13 patients, and below $1 \mu \mathrm{g} / \mathrm{l}$ in 7 of these. In 9 patients out of these 13, a marked rise in GH levels occurred after nadir. Baseline and nadir GH values of these 9 patients were not different from the corresponding values of the other 4 patients without OGTT-induced late GH peaks.

Conclusions: GH rebound after GH nadir occurs in acromegalic patients considered as cured on the basis of OGTT-induced GH suppression and/or IGF-I normalization. The restoration of this physiological response could be regarded as a marker of recovered/preserved integrity of the hypothalamic-pituitary axis. Even though the reason for this GH rebound has not yet been elucidated (GHRH discharge?/end of somatostatin inhibition?), the lack of late GH peak in the patients regarded as cured by the usual criteria could be due to injury to the pituitary stalk caused by the adenoma or by surgical manipulation.
\end{abstract}

European Journal of Endocrinology $14023-28$

\section{Introduction}

The restoration of growth hormone $(\mathrm{GH})$ suppression following an oral glucose (Glc) tolerance test (OGTT) is considered the gold standard for evaluating successful treatment of acromegaly after surgery (1) and the normalization of insulin-like growth factor-I (IGF-I) levels represents the aim of both surgical and medical treatment. Other criteria to evaluate cure of acromegalic patients include the disappearance of paradoxical stimuli for GH secretion, such as thyrotropin-releasing hormone (TRH) (2), and the restoration of normal GH dynamics (3).

It is known that in normal subjects a rebound of GH levels is frequently observed after the suppressive effect of an OGTT (4). This phenomenon has not yet been assessed in acromegalic patients. Therefore we felt it of interest to evaluate GH levels after an OGTT, by prolonging blood sampling up to $300 \mathrm{~min}$, in a large series of operated acromegalic patients, with the aim of disclosing the restoration of normal GH dynamics following removal of the adenoma.

\section{Patients and methods}

\section{Patients}

Acromegalic patients recently submitted to neurosurgical treatment entered the study after giving informed consent. All patients had been operated on by a single surgical team, following a clearly defined protocol.

Acromegaly had been diagnosed because of the clinical picture, GH levels not suppressible by oral Glc load to less than $2 \mu \mathrm{g} / \mathrm{l}$, and high IGF-I levels for age. Exclusion criteria were neurosurgery via an approach different from the transsphenoidal, hypopituitarism (as demonstrated by levels of free thyroid hormones, plasma cortisol or urinary free cortisol, plasma testosterone or estradiol below the normal range) or previous radiotherapy. No patient was affected by diabetes mellitus, active hepatic or 
renal disease. All subjects were within $20 \%$ of ideal body weight, even though it should be underlined that a larger value in acromegalic patients compared with normal subjects does not mean that the patients have an increased mass of fat tissue. It is well known that the lean body mass in this disease is increased (5).

Twenty-nine acromegalic patients (13 males, 16 females, age range 27-70 years) fulfilled these criteria and were evaluated. Individual demographic and clinical data are reported in Table 1. Hyperprolactinemia was present in eight patients (\# 3, 5, 8, 13, 17, 20, $25,28)$. At the preoperative neuroradiological imaging by high resolution CT scan or MRI, tumor sizes were classified into three groups: microadenomas $(n=7)$; intrasellar macroadenomas $(n=8)$; and tumors with extrasellar expansion $(n=14)$.

Patients underwent an OGTT 3-6 months after neurosurgery, as outpatients. No patient was on any drug treatment aimed at lowering GH hypersecretion or potentially capable of interfering with $\mathrm{GH}$ secretion.

Blood samples were collected in the morning, after an overnight fast and rest, while the patients were supine and awake, with an indwelling needle inserted in an antecubital vein and kept patent by slow saline infusion. Plasma GH levels were assayed basally every $15 \mathrm{~min}$ three times, thereafter patients were submitted to an OGTT (75 g Glc p.o.) with determination of GH and Glc levels every $30 \mathrm{~min}$ up to $180 \mathrm{~min}$ and then hourly up to $300 \mathrm{~min}$ after Glc administration. IGF-I was evaluated in the first basal sample.

\section{Methods}

GH and IGF-I were assayed in duplicate by an immunoenzymatic method and RIA after acid-ethanol extraction respectively. Plasma Glc was assessed by standard methods (Glc oxidase). All samples from a patient were run together.

Reagents were purchased from Sorin (Saluggia, Italy) for GH and Nichols (San Juan de Capistrano, CA, USA) for IGF-I.

Standards were calibrated against 1st IS 80/505 ( $1 \mathrm{ng}=2 \mu \mathrm{IU}$ ) for $\mathrm{GH}$ and WHO $87 / 518$ for IGF-I.

Table 1 Demographic and clinical data.

\begin{tabular}{|c|c|c|c|c|c|c|c|}
\hline No. & Sex & Age (years) & $\mathbf{T C} / \mathrm{MRI}^{1}$ & $|G F-|^{2}$ & IGF-I $(\%)^{3}$ & Basal GH ${ }^{4}$ & Nadir $\mathbf{G H}^{5}$ \\
\hline 1 & $\mathrm{~F}$ & 63 & $\mu$ & 342 & 118 & 2.2 & 1.4 \\
\hline 2 & $\mathrm{~F}$ & 70 & EX & 220 & 76 & 1.6 & 1.1 \\
\hline 3 & $M$ & 65 & $\mu$ & 400 & 138 & 3.2 & 2.2 \\
\hline 4 & $\mathrm{~F}$ & 65 & $M$ & 320 & 110 & 2.0 & 0.9 \\
\hline 5 & $\mathrm{~F}$ & 40 & EX & 492 & 137 & 15.1 & 9.9 \\
\hline 6 & $\mathrm{~F}$ & 54 & EX & 490 & 136 & 2.3 & - \\
\hline 7 & $\mathrm{~F}$ & 65 & EX & 400 & 138 & 24.3 & 2.6 \\
\hline 8 & $\mathrm{~F}$ & 48 & EX & 253 & 70 & 1.5 & 1.0 \\
\hline 9 & $M$ & 53 & $M$ & 395 & 110 & 1.0 & 0.4 \\
\hline 10 & $\mathrm{~F}$ & 32 & EX & 1000 & 203 & 19.1 & 10.3 \\
\hline 11 & $M$ & 50 & $\mathrm{M}$ & 650 & 181 & 7.9 & 7.4 \\
\hline 12 & $M$ & 56 & $\mu$ & 275 & 95 & 2.4 & - \\
\hline 13 & $M$ & 52 & EX & 900 & 250 & 7.7 & 5.9 \\
\hline 14 & $\mathrm{~F}$ & 58 & $\vec{M}$ & 620 & 214 & 4.3 & 3.0 \\
\hline 15 & $M$ & 50 & EX & 359 & 100 & 2.1 & 0.1 \\
\hline 16 & $M$ & 55 & EX & 205 & 71 & 0.4 & 0.4 \\
\hline 17 & $\mathrm{~F}$ & 33 & $M$ & 362 & 74 & 2.5 & 0.5 \\
\hline 18 & $\mathrm{~F}$ & 40 & $M$ & 850 & 236 & 8.7 & 7.2 \\
\hline 19 & $M$ & 40 & EX & 388 & 108 & 2.5 & - \\
\hline 20 & $\mathrm{~F}$ & 27 & EX & 280 & 57 & 5.7 & 3.9 \\
\hline 21 & $M$ & 48 & $\mu$ & 206 & 57 & 2.0 & 0.1 \\
\hline 22 & $\mathrm{~F}$ & 38 & $\mu$ & 520 & 106 & 8.3 & 3.3 \\
\hline 23 & $\mathrm{~F}$ & 64 & $\mu$ & 383 & 132 & 4.1 & 2.7 \\
\hline 24 & $\mathrm{~F}$ & 42 & $M$ & 283 & 79 & 2.2 & 1.9 \\
\hline 25 & $M$ & 51 & EX & 300 & 83 & 3.0 & 1.0 \\
\hline 26 & $M$ & 50 & EX & 626 & 174 & 2.4 & - \\
\hline 27 & $\mathrm{~F}$ & 42 & $\mu$ & 236 & 66 & 8.1 & 1.5 \\
\hline 28 & $M$ & 38 & EX & 343 & 70 & 0.2 & 0.1 \\
\hline 29 & $M$ & 44 & $M$ & 500 & 139 & 3.2 & 3.0 \\
\hline
\end{tabular}

\footnotetext{
${ }^{1}$ Presurgical neuroradiological imaging: $\mu=$ microadenoma, $\mathrm{M}=$ intrasellar macroadenoma, $\mathrm{EX}=$ macroadenoma with extrasellar extension.

${ }^{2}$ In $\mu \mathrm{g} / \mathrm{l}$. Normal IGF-I values in our laboratory are 114-492 $\mu \mathrm{g} / \mathrm{l}$ in patients $25-39$ years old, 90-360 $\mu \mathrm{g} / \mathrm{l}$ in patients $40-54$ years old, $71-$ $290 \mu \mathrm{g} / \mathrm{l}$ in patients older than 55 years.

${ }^{3}$ Expressed as percent of the upper limit of the normal age-adjusted range.

${ }^{4}$ In $\mu \mathrm{g} / \mathrm{l}$, mean of three samples.

${ }^{5} \mathrm{GH}$ nadir in $\mu \mathrm{g} / \mathrm{l}$ during OGTT, - = no decrease or paradoxical increase.
} 
Intra-assay coefficients of variation were $3.5 \%$ for $\mathrm{GH}$ and $3.7 \%$ for IGF-I.

Normal values in our laboratory for IGF-I are: 114$492 \mu \mathrm{g} / \mathrm{l}$ in patients 25-39 years old, 90-360 $\mu \mathrm{g} / \mathrm{l}$ in patients $40-54$ years old, $71-290 \mu \mathrm{g} / \mathrm{l}$ in patients older than 55 years.

For GH levels the detection limit was $0.1 \mu \mathrm{g} / \mathrm{l}$.

\section{Statistical analysis}

Values are expressed as median and range, due to nonnormal distribution. Basal GH levels are the mean of the three samples collected before Glc administration. Areas under curves (AUCs) were calculated by trapezoidal integration, subtracting basal values: $\mathrm{AUC}_{0-150}$ between 0 and $150 \mathrm{~min}, \mathrm{AUC}_{150-300}$ between 150 and $300 \mathrm{~min}$. $\mathrm{GH}$ rebound was arbitrarily defined as a GH increase after Glc-induced suppression that was greater than $10 \mu \mathrm{g} / \mathrm{l}$. IGF-I values are expressed both as absolute values and as percentages of the upper limit of the normal age-adjusted range.

Data were analyzed by Student's t-test, MannWhitney test, Wilcoxon test, Kruskall-Wallis ANOVA followed by Dunn's test, Pearson correlation test, or McNemar's test, as appropriate.

Values of $P$ less than 0.05 were considered significant.

\section{Results \\ Basal GH levels}

GH was below $2 \mu \mathrm{g} / \mathrm{l}$ in 5 patients (\# 2, 8, 9, 16, 28) (two out of these, \# 16 and 28 , had levels $<1 \mu \mathrm{g} / \mathrm{l}$ ), ranged between 2 and $5 \mu \mathrm{g} / \mathrm{l}$ in 15 (\# 1, 3, 4, 6, 12, 14, $15,17,19,21,23-26,29)$, and was $\geq 5 \mu \mathrm{g} / \mathrm{l}$ in 9 (\# 5, $7,10,11,13,18,20,22,27)$.

\section{IGF-I levels}

In 12 patients (\# 2, 8, 12, 15-17, 20, 21, 24, 25, 27, 28), normal age-adjusted values were reached. Among the other 17 patients, 11 (\# 1, 3-7, 9, 19, 22, 23, 29) achieved IGF-I values ranging between 101 and 140\% of the upper limit of the normal age-adjusted range.

\section{OGTT}

$\mathrm{GH}$ values were suppressed from $2.5 \mu \mathrm{g} / \mathrm{l}(0.2-24.3)$ to $1.9 \mu \mathrm{g} / \mathrm{l}(0.1-10.3)$ in the whole group $(P=0.006)$. The analytical evaluation showed that in 16 out of 29 patients, GH did not decrease below $2 \mu \mathrm{g} / \mathrm{l}$. In the remaining 13 patients (\# 1, 2, 4, 8, 9, 15-17, 21, $24,25,27,28)$, GH levels fell below $2 \mu \mathrm{g} / \mathrm{l}$ and in 7 out of these (\# 4, 9, 15-17, 21, 28), GH nadir was below $1 \mu \mathrm{g} / \mathrm{l}$.

On considering as cut-off OGTT-induced GH levels $<2 \mu \mathrm{g} / \mathrm{l}$ and normal age-adjusted IGF-I values, the patients fell into two categories:
Group I - 13 patients with GH levels below $2 \mu \mathrm{g} / \mathrm{l}$ after Glc load. Ten of them (\# 2, 8, 15-17, 21, 24, 25, $27,28)$ reached normal age-adjusted IGF-I levels. In the remaining three patients (\# 1, 4, 9), IGF-I levels remained pathological but their individual IGF-I levels were near normal, i.e. 118, 110, and $110 \%$ of the upper limit of the normal age-adjusted range respectively.

Group II - 16 patients with GH levels greater than $2 \mu \mathrm{g} / \mathrm{l}$ after Glc load. Fourteen of them (\# 3, 5-7, 10, $11,13,14,18,19,22,23,26,29)$ had pathological IGF-I levels, whereas in two patients (\# 12, 20) normal age-adjusted IGF-I levels were obtained.

If patients belonging to the two groups were distinguished according to the presurgical tumor size, no significant difference was observed in outcome.

\section{Evaluation of the whole OGTT-induced GH curve}

A rebound burst of $\mathrm{GH}$ release $(\geq 10 \mu \mathrm{g} / \mathrm{l})$ was observed in 9 (\# 1, 4, 15-17, 21, 25, 27, 28) out of the 13 patients belonging to Group I (regarded as cured) (Fig. 1). It occurred between 180 and $240 \mathrm{~min}$ after Glc load and ranged between 8 and 200 times the nadir value. The basal GH level in these 9 patients was $2.1 \mu \mathrm{g} / \mathrm{l}$ (0.2-8.1), OGTT-induced GH nadir was $0.5(0.1-$ 1.5) $\mu \mathrm{g} / \mathrm{l}$, late peak was $14.4(10.7-19.1) \mu \mathrm{g} / \mathrm{l}$; IGF-I was $320(205-362) \mu \mathrm{g} / \mathrm{l}$. Basal GH $(1.6 \mu \mathrm{g} / \mathrm{l}(1.0-$ $2.2))$, GH nadir after Glc load $(1.1 \mu \mathrm{g} / \mathrm{l}(0.4-1.9))$, and IGF-I $(268 \mu \mathrm{g} / \mathrm{l}(220-395))$ values of the other four patients (\# 2, 8, 9, 24) without OGTT-induced late GH peaks were not different from the corresponding values of the nine patients reported above. No difference was observed in Glc nadir between the two groups. On the other hand, individual analysis of OGTT-induced GH nadir in these two groups showed GH below $1 \mu \mathrm{g} / \mathrm{l}$ in six of nine of the rebound group vs one of four in the group without rebound.

On examining the AUCs of GH, a significant difference was observed only in the final portion of the OGTT curve, i.e. after $150 \mathrm{~min}(801 \quad(468-1832) \mu \mathrm{g} / \mathrm{l}$ per $150 \mathrm{~min}$ in patients with rebound vs $140.5(-23$ to $+177) \mu \mathrm{g} / \mathrm{l}$ per $150 \mathrm{~min}$ in patients without rebound, $P=0.006)$, whereas the difference was not significant in the first part of the curve $(-141(-350$ to +27$) \mu \mathrm{g} / \mathrm{l}$ per $150 \mathrm{~min}$ in patients with rebound vs $-25(-65$ to $+17) \mu \mathrm{g} / \mathrm{l}$ per $150 \mathrm{~min}$ in patients without rebound).

Finally there was a significant inverse correlation ( $r=-0.94, \quad P=0.017$ ) between GH rebound and plasma Glc nadir. Once again, if these 13 patients were divided according to presurgical tumor size, no significant difference was observed in the occurrence of $\mathrm{GH}$ rebound. No GH rebound was observed in the 16 patients belonging to Group II.

\section{Discussion}

In the present study we report for the first time the restoration of GH rebound after OGTT-induced nadir in 


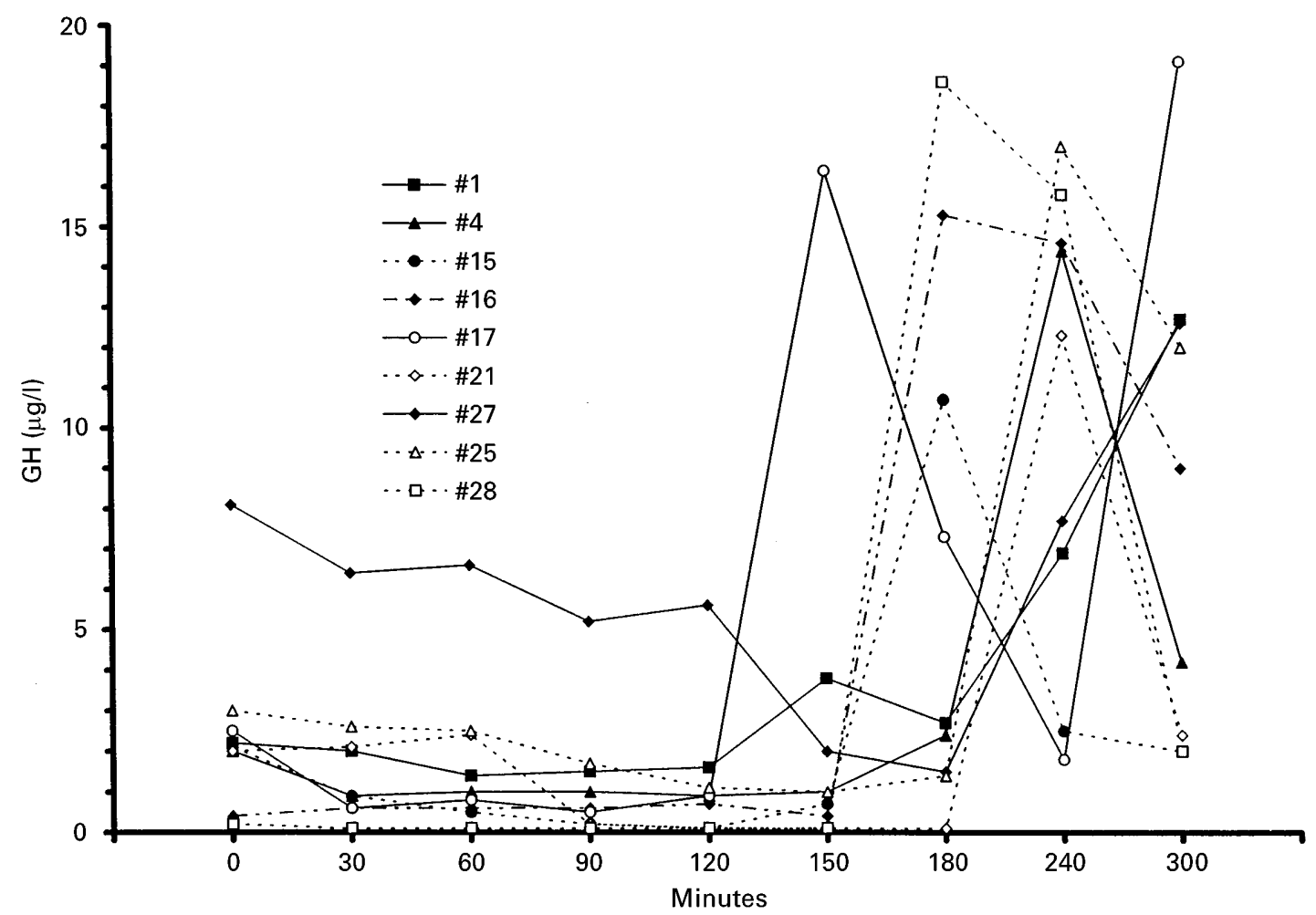

Figure 1 Individual plasma levels of GH after an OGTT (75 g p.o. at time 0) obtained in the nine patients with late GH burst.

surgically cured acromegalics. This GH rebound (i.e. increase of $\mathrm{GH}$ levels $>10 \mu \mathrm{g} / \mathrm{l}, 8-200$ times the nadir value, and of AUC in the late portion of the sampling period) was observed in nine patients. In all these nine patients $\mathrm{GH}$ fell below $2 \mu \mathrm{g} / \mathrm{l}$ in the hyperglycemic phase of the OGTT (and below $1 \mu \mathrm{g} / \mathrm{l}$ in seven of them) and normal age-adjusted IGF-I values were obtained in seven (and near-normal in the other two patients). This phenomenon was observed in patients assumed to maintain a normally working hypothalamo-pituitary connection. These patients fulfilled the strict criteria reported in the Methods section, i.e. lack of pituitary failure, transsphenoidal surgery by the same neurosurgeon and no previous radiotherapy. The temporal relationship between OGTT-induced GH nadir and the subsequent burst of GH secretion (shaped as a curve in all the patients) seems to point to hormonal rebound, quite different from the occurrence of spontaneous fluctuations or secretory spikes. The inverse correlation between $\mathrm{GH}$ rebound and nadir Glc levels in the final phase of the OGTT could be regarded as further evidence that this $\mathrm{GH}$ burst is not a spontaneous peak.

We are not aware of previous results on this topic in acromegalic patients, whereas it has already been described in normal subjects. Glc administration has a biphasic effect on $\mathrm{GH}$ secretion in man. Following oral Glc, initial plasma GH suppression is followed by a marked rise (4). Only few data about the late GH peak in normal subjects are available; indeed a wide variability of GH rebound after Glc administration was reported, as well as a poor or absent $\mathrm{GH}$ response in some individuals (6). Moreover, the reproducibility of this response is still to be demonstrated. The mechanism mediating the GH response to Glc is not yet fully elucidated. GH secretion is regulated mainly by the interplay between the hypothalamic hormones, growth hormone-releasing hormone $(\mathrm{GHRH})$ and somatostatin $(\mathrm{SRIH})(7)$, so that changes of these peptides are likely to be involved. Direct experimental evidence for this hypothesis is the lack of Glc effect on $\mathrm{GH}$ and thyrotropin release from rat pituitary cells in vitro (8) and the inverse relationship between Glc concentration and SRIH release from rat hypothalamic cells in vitro $(9,10)$. The clinical counterpart of this experimental evidence is Glc-induced block of $\mathrm{GH}$ response to stimuli acting at the suprapituitary level, such as arginine (11), exercise (12) and L-DOPA (13). All these data seem to imply that the action of Glc on GH release is exerted by a stimulation of hypothalamic SRIH.

As for the late GH rise after Glc administration, some hypotheses have been put forward. GHRH may be involved; when Glc is administered $3.5 \mathrm{~h}$ before GHRH, GH release is enhanced (14). Valcavi (6) hypothesized that oral Glc administration could enhance hypothalamic SRIH release, thus blunting plasma $\mathrm{GH}$ levels for $2-3 \mathrm{~h}$. In this phase $\mathrm{GH}$ should be stored at the pituitary level; as SRIH tone fades and 
endogenous GHRH resumes its activity, GH is released from pituitary stores, and a rebound in serum GH levels is observed.

The persistence of an SRIH tone in some patients with active acromegaly whose hypothalamus-pituitary network was intact has already been reported $(15,16)$. It was hypothesized that the high somatostatinergic tone induced by high circulating GH and IGF-I levels could not be further stimulated but could be suppressed in those patients.

Whatever the mechanism of this phenomenon (GHRH discharge?/end of SRIH inhibition?), GH rebound could be regarded as a marker of recovered integrity of the hypothalamic-pituitary axis and of normal $\mathrm{GH}$ secretion by pituitary cells. In contrast the lack of a late $\mathrm{GH}$ peak in the remaining patients regarded as cured by standard criteria could be due to injury to the pituitary stalk caused by the adenoma or by surgical manipulation. We hypothesize that, even though the injury is not great enough to cause pituitary failure, it might have provoked a subtle alteration in the delicate interplay of hypothalamic-pituitary hormones regulating $\mathrm{GH}$ secretion. In addition a lack of SRIH tone may be suggested.

As for the five patients of this series with conflicting $\mathrm{GH}$ and IGF-I values, it is disappointing to find a discrepancy. A discordance between GH and IGF-I levels has already reported in some acromegalic patients. Wass (17) reported normal GH values with elevated IGF-I levels in $8 \%$ of 73 acromegalics off medical treatment and normal IGF-I values with GH levels still high in $19 \%$ of cases. Indeed GH suppression after the OGTT and IGF-I levels reflect different physiopathological mechanisms, i.e. the integrity of GH neuroregulation and the normalization of integrated daily concentration of GH respectively. As for the three patients with normal GH suppression after an OGTT and near normal IGF-I values, normally working hypothalamo-pituitary connections may be suggested, in the face of the persistence of a very low degree of $\mathrm{GH}$ hypersecretion due to the occurrence of abnormally frequent pulses of secretion (18). In contrast, for the two patients with normal IGF-I values but unsatisfactory suppression of $\mathrm{GH}$ after Glc load, a subtle disruption of the integrity of the hypothalamo-pituitary network can be hypothesized. Perhaps further evaluation in a larger series of patients with conflicting data between OGTT-induced GH suppression and IGF-I levels might show whether prolonged $\mathrm{GH}$ sampling after oral Glc administration could have a clinical usefulness in the evaluation of the surgical cure of acromegaly.

In summary, the present criteria of cure for acromegaly include the restoration of $\mathrm{GH}$ suppression after an OGTT and the normalization of IGF-I levels. Additional criteria of cure, i.e. the disappearance of paradoxical $\mathrm{GH}$ responses, such as to $\mathrm{TRH}$, and the restoration of normal GH diurnal rhythm, are suggestive of the restoration of normal GH pathophysiology.
The occurrence of late GH rebound to Glc in cured acromegalics, reported for the first time in this paper, could be regarded as a further tool in the evaluation of restoration of normal GH pathophysiology after neurosurgery. The follow-up of these patients will perhaps allow us to establish if the occurrence of GH rebound after Glc suppression may be predictive of ultimate cure.

\section{References}

1 Melmed S, Ho K, Klibanski A, Reichlin S \& Thorner MO. Recent advances in pathogenesis, diagnosis, and management of acromegaly. Journal of Clinical Endocrinology and Metabolism $1995803395-3402$

2 Arosio M, Giovanelli MA, Riva E, Ambrosi B \& Faglia G. Clinical use of pre- and postsurgical evaluation of abnormal GH responses in acromegaly. Journal of Neurosurgery 1983 9 402-408.

3 Jacquet $\mathrm{P}$, Guibout $\mathrm{M} \&$ Jacquet $\mathrm{C}$. Circadian regulation of growth hormone secretion after treatment in acromegaly. Journal of Clinical Endocrinology and Metabolism 198050 322-328.

4 Roth J, Glick SM, Yalow RS \& Berson SA. Secretion of human growth hormone: physiologic and experimental modification. Metabolism 196312 577-579.

5 Bengtson BA, Brummer RJ \& Bossaeus I. Growth hormone and body composition. Hormone Research 19904 (Suppl) 19-24.

6 Valcavi R. Oral glucose tolerance test: an inhibitory or stimulatory input to growth hormone secretion? Journal of Endocrinological Investigation 199619 253-255.

7 Tannenbaum GS. Interrelationship of somatostatin and growth hormone-releasing hormone in the genesis of the rhythmic secretion of growth hormone. Acta Pediatrica Scandinavica 1990 367 (Suppl) 76.

8 Shibasaki T, Masuda A, Hotta M, Yamauchi N, Hizuka N. Takano K, Demura H \& Shizume K. Effects of ingestion of glucose on GH and TSH secretion: evidence for stimulation of somatostatin release from the hypothalamus by acute hyperglycemia in normal man and its impairment in acromegalic patients. Life Sciences 198944 431-438.

9 Lengyel AMJ, Nieuwenhuyzen-Kruseman AC, Grossman A, Rees L \& Besser GM. Glucose-induced changes in somatostatin-14 and somatostatin-28 released from rat hypothalamic fragments in vitro. Life Sciences 198435 713-719.

10 Berelowitz M, Dudlak D \& Frohman LA. Release of somatostatinlike immunoreactivity from incubated rat hypothalamus and cerebral cortex. Effects of glucose and glucoregulatory hormones. Journal of Clinical Investigation 198269 1293-1301.

11 Burday SZ, Fine PH \& Schalch DS. Growth hormone secretion in response to arginine infusion in normal and diabetic subjects: relationship to blood glucose levels. Journal of Laboratory and Clinical Medicine 196871 897-911.

12 Hansen AP. The effect of intravenous glucose infusion on the exercise-induced serum growth hormone rise in normals and juvenile diabetics. Scandinavian Journal of Clinical and Laboratory Investigation 197128 195-205.

13 Mims RB, Scott CL, Modebe OM \& Bethune JE. Prevention of Ldopa-induced growth hormone stimulation by hyperglycemia. Journal of Clinical Endocrinology and Metabolism 197337 660663.

14 Valcavi R, Zini M, Dieguez C, Portioli I \& Scanlon MF. Effect of oral glucose on the late growth hormone rise and growth hormone responses to GHRH in normal subjects. Clinical Endocrinology $199032539-543$.

15 Attanasio R, Cozzi R, Oppizzi G, Dallabonzana D, Chiodini I, Benini Z, Orlandi P, Liuzzi A \& Chiodini PG. Persistence of somatostatinergic tone in acromegaly. European Journal of Endocrinology 1995132 27-31.

16 Yang I, Park S, Woo J, Kim S, Kim J, Kim Y \& Choi Y. Growth hormone response to the hypothalamic somatostatinergic activity 
in acromegalic patients. Journal of Clinical Endocrinology and Metabolism 199782 2492-2496.

17 Wass JAH. Growth hormone, insulin-like growth factor-I and its binding proteins in the follow-up of acromegaly. Journal of Endocrinology 1997155 (Suppl) S17-S19.

18 Ho PJ, Jaffe CA, Demott Friberg R, Chandler WF \& Barkan AL. Persistence of rapid growth hormone $(\mathrm{GH})$ pulsatility after successful removal of GH-producing pituitary tumors. Journal of Clinical Endocrinology and Metabolism 199478 1403-1410.

Received 9 October 1998

Accepted 12 October 1998 